\title{
Get an international audience for your research without leaving your office
}

\section{Martyn Pickersgill}
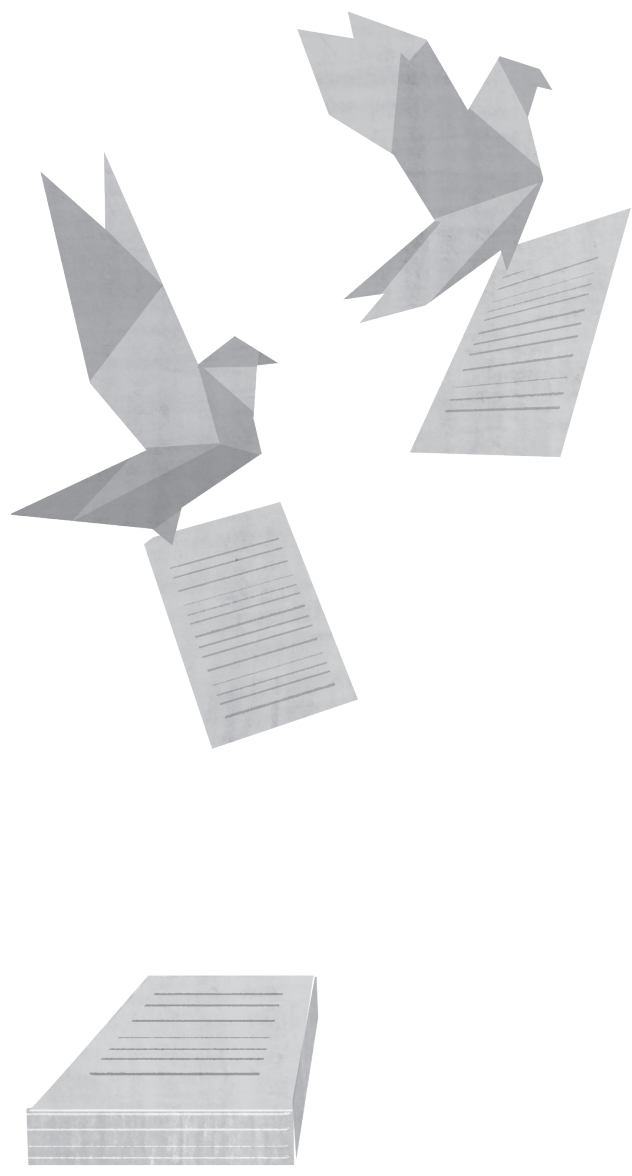

International invitations to visit other universities and speak at conferences are a key way of disseminating your research and showing international impact - and hence represent a major criterion for promotion to senior (reader/professor) university positions. Yet, international travel can be challenging for those with caring responsibilities, and we know that women disproportionately bear this load (Gaio Santos \& Cabral-Cardoso, 2008). Further, monies for international travel are often part of the discretionary funds made available to principal investigators through grants. However, these monies can relate to salaries, and we also know that there is a gender gap in pay especially at $\mathrm{mid} /$ senior career levels, with men faring better (UCU, 2016).

These organisational and cultural factors place limits on the extent to which women, especially, are able to disseminate their work and evidence international impact - and hence progress into leadership positions. Social media - specifically, Twitter - can provide a means a generating an international 'presence' without leaving your office. New ways of measuring journal impact - such as altmetrics - can quantify the amount of attention your research is getting online, for example by measuring tweets and retweets about your work. Hence, the attention generated by your work on Twitter can be quantified for the purposes of promotion and related applications 
(Botting et al., 2017). For example, the University of Edinburgh's promotion guidance relating to excellence in knowledge exchange rewards engagement with media including "significant social media outlets" in which researchers contribute "significantly to public debate and enlightenment" (Exemplars of Excellence, 2015).

Finally, Twitter can be a good means of getting to know other research and academics - especially early-career scholars - that are of relevance to your field. Indeed, a study of academics' use of social media for scholarly purposes suggested that the overwhelming motivation for women/ female researchers was reported as: "To be part of a professional community".

\section{Ingredients}

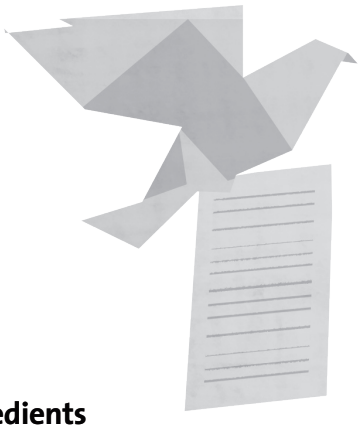

- A working Internet connection.

- A Twitter account.

- A willingness to speak out about your research.

\section{Method}

1. Open a Twitter account, and chose a username that will make you easy to find - for example, your name.

2. Start following your colleagues, and key people in your field. Over time, you'll also get a sense for other academics who regularly tweet with authority about issues of relevance to your work (e.g. science policy, equality and diversity), but who are not necessarily in your discipline.

3. Start tweeting! You can retweet things you think are relevant and/or important. Experiment with your own original tweets.

4. Your tweets might be about a paper you're reading at the moment that you find particularly interesting, or details of a conference you think would be relevant to people who follow you (and people who you'd like to be followed by).

5. If you're a mid-career or senior academic, make sure you use your account to promote the work and achievements of early-career researchers (ECRs) - and try to follow ECRs back if they follow you.

6. Every so often, tweet about your own work. When you've got a paper accepted, tweet about it and tag the journal. 


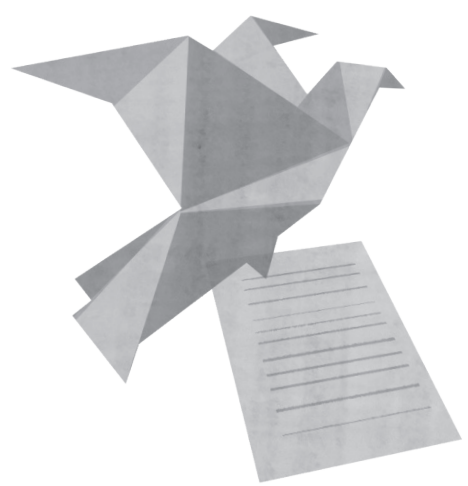

When it's in press, let people know when it's online. When it's out, tweet the title, and later on some of the questions it addresses. There's no harm in tweeting about the paper a few times over the course of a week once it's out (but probably no more than twice a day, maximum). Being blunt about your work and achievements can feel uncomfortable, but it's far better than the 'humblebrag' ("My new Nature paper probably won't be of interest to anyone..."). Just say that you're pleased about the paper/invitation/prize and give the link, or just list the article title and a link.

7. If people tweet nice things about your work, or those of your colleagues (again, especially ECRs), retweet them and thank them.

8. If there's a key issue igniting the passions of the twitterati at a particular time (regarding your discipline specifically, or in society more generally), don't be afraid to tweet past work if it relates to wider current concerns or debate.

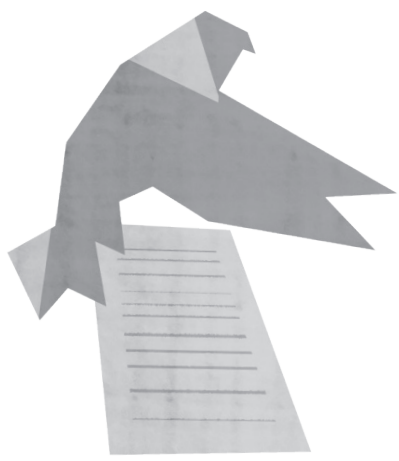

\section{Cook's tips}

Make sure to use hashtags, which will make your tweet more discoverable (e.g. \#ClimateChange, \#SocialScience, \#WomenInScience, etc). If mentioning other people, make sure to use their Twitter handle rather than their name.

Remember that people are likely to be following you because they are interested in your work, not because you post exactly the same newspaper article that all the other people they follow are also tweeting about.

\section{Warning}

Don't overdo it! Twitter can be a great way to find out about new work and researchers, about trends and concerns in your discipline, and to get the message out about your own and colleagues' scholarship. But it can also be incredibly distracting! Also, while Twitter is a great way to promote your research, you won't win many people over if that's the only thing you use it for. 